\title{
Red Iberoamericana de Estudios sobre Oralidad: constitución y prospectiva
}

\section{Yolima Gutiérrez Ríos*}

El Primer Encuentro Iberoamericano de Estudios sobre Oralidad y IV Encuentro Latinoamericano de Identidades. "La oralidad en contextos diversos", realizado en Bogotá del 8 al 10 de junio de 2011, simboliza el interés creciente de un movimiento de profesores e investigadores de diversos puntos de la geografía mundial, motivado por el estudio de la oralidad en contextos diversos. Se trata de un interés renovado por lo oral y sus modos de representar la cultura, recrear y significar el mundo e intervenir en el desarrollo cognitivo, comunicativo e identitario del sujeto.

Esta convergencia posibilitó el intercambio de saberes y experiencias de colectivos de docentes e investigadores provenientes de las ciencias sociales, las ciencias del lenguaje y la comunicación, la literatura y la educación, entre otras. La riqueza de sus desarrollos evidencia un gran aporte al campo de la oralidad y particularmente a la emergencia de nuevas problemáticas, al reconocimiento de futuras líneas de investigación y a la consolidación de perspectivas teóricas y metodológicas.

Cabe señalar que en el marco de la investigación "Análisis de las concepciones disciplinares y didácticas sobre la lengua oral en la escuela colombiana actual: Un estudio sobre el desarrollo de la competencia discursiva oral en la educación media"', se realiza un estado del arte de la oralidad en la última década, el cual permite reconocer nuevas y diversas formas de abordarla y valorarla, junto con la detección de cuatro orientaciones o tendencias contemporáneas: la perspectiva antropológica y sociocultural de la oralidad; la perspectiva literaria; la perspectiva retórica, lingüística y discursiva de la oralidad, y la perspectiva educativa.

De este modo, el encuentro se organizó fundamentalmente alrededor de estas perspectivas como ejes orientadores de los diferentes trabajos e investigaciones en Iberoamérica sobre oralidad. 1. eje antropológico y sociocultural de la oralidad; 2 . eje de la literatura y la oralidad; 3. eje retórico, lingüístico y discursivo de la oralidad; 4. eje pedagógico y educativo de la oralidad.

Así, pues, en este primer encuentro de colectivos que indagan sobre la oralidad se avivaron las relaciones oralidad-lenguaje, oralidad-cultura, oralidad-sociedad y oralidad-subjetividad. Además, se cumplió con el propósito de impulsar la creación de la red de estudios sobre oralidad en la perspectiva de contribuir a la constitución de un espacio interinstitucional de encuentro que favorezca la construcción e intercambio de saberes, líneas de investigación, proyectos y experiencias derivadas de los distintos campos disciplinares en los que se estudia la oralidad.

En Colombia y en diferentes países la constitución de redes de maestros ha puesto de manifiesto las

\footnotetext{
* Profesora de la Normal Superior Distrital María Montessori y de la Universidad Distrital Francisco José de Caldas Bogotá, Colombia. Correo: yolimag@yahoo.es

1 Tesis doctoral realizada por Yolima Gutiérrez, bajo la dirección de las Dras. María Elvira Rodríguez Luna y Gladys Jaimes de Casadiego, Grupo de Investigación Lenguaje, Cultura e Identidad.
} 
posibilidades de acción de la escuela ${ }^{2}$. El espíritu colegiado de los grupos de investigación que operan mediante redes constituye un nuevo desafío y un espacio de formación permanente e integral que favorece el desarrollo profesional del docente, fortalece otras formas de interacción y, sobre todo, potencia la confluencia de pensamientos y discursos interesados en transformar las realidades escolares y sociales (Jaimes, Bojacá y Morales, 2006).

Estas búsquedas y planteamientos respecto de las problemáticas derivadas de la oralidad confluyen en una Red de Estudios, no solo como resultado de una investigación centrada en la enseñanza de la lengua oral en Colombia, sino también como un espacio de confluencia de distintos grupos de investigación con intereses comunes. Por ello, entre los propósitos de la Red Iberoamericana de Estudios sobre Oralidad se contemplan procesos de autoformación docente y de autonomía en la colegialidad, como constructos propios de un programa de formación en redes orientado al desarrollo profesional docente desde un proyecto común (Imbernón, 2009) coherente con el ideal de un profesor investigador que participa en proyectos de impacto académico y social.

Así, pues, este primer encuentro contó con investigadores y profesores provenientes de distintos puntos de las geografía iberoamericana e incluso europea, quienes fungieron como conferencistas y ponentes en el Encuentro convocado por los grupos Lenguaje, Cultura e Identidad y de Maestría en Pedagogía de la Lengua Materna, de la Universidad Distrital Francisco José de Caldas de Bogotá (Colombia); Oralidad, Tradición y Cultura Popular, de la Universidad Iberoamericana (México D.F.); FesAcatlán de la UNAM (Estado de México); Étimo, de la Universidad de Granada (España); y La Sociedad Española de Didáctica de la Lengua y la Literatura, conformados por educadores de Colombia, México y España, respectivamente. Entre otras proyecciones sobresalen las siguientes:

La Red Iberoamericana de Estudios sobre Oralidad nace, entonces, como una entidad jurídica y sin ánimo de lucro auspiciada por la voluntad de colectivos de investigadores de diversos países (Colombia, México, España, Chile, Perú, Venezuela, entre otros) reunidos en este Primer Encuentro Iberoamericano de Estudios sobre Oralidad y IV Encuentro Latinoamericano de Identidades. Por lo anterior, se otorgó el carácter de miembro de la Red a todos los participantes en este Primer Encuentro, con la perspectiva de impulsar en cada uno de los nodos nacionales y regionales formas de organización que posibiliten la consolidación de comunidades de conocimiento y de práctica sobre la oralidad.

Para la consecución y fortalecimiento de los anteriores avances también se acordó la realización de encuentros cada dos años en los diferentes países que constituyen la Red, de modo que el siguiente sería el Segundo Encuentro Iberoamericano de Estudios sobre Oralidad y V Encuentro Latinoamericano de Identidades. Esta proyección dio como resultado la postulación de Granada (España) como próxima sede del encuentro a realizarse en 2013, propuesta por los grupos Étimo de la Universidad de Granada y La Sociedad Española de Didáctica de la Lengua y la Literatura.

2 Red Colombiana para la Transformación de la Formación docente en Lenguaje surge del interés de distintos grupos de investigación provenientes de distintas universidades del país (Distrital, Nacional y del Valle, entre otras) por el campo del lenguaje; Red IRES surge como iniciativa de las Universidades de Sevilla, Madrid y Cádiz (España), la Red TEBES como propuesta de la Universidad Pedagógica Nacional (México) y la Red CEE desde la Universidad Pedagógica Nacional (Colombia). 
En este momento se avanza en los procesos organizativos y jurídicos que posibiliten la acción de la Red en distintos campos sociales y académicos. Así mismo, se proyecta el funcionamiento de la página Web de La Red Iberoamericana de Estudios sobre Oralidad, desde la cual se actualizará la gestión de las diferentes redes nacionales y sus nodos regionales, como también el desarrollo de labores de divulgación de las producciones académicas, artísticas y culturales que surjan de los distintos grupos de estudio, de investigación y de acción social, a través de una revista electrónica. 